\title{
INCLUSÃO DE PROJETOS NA ÁREA DE ELETRÔNICA EM ESCOLAS PÚBLICAS DO MUNICÍPIO DE MARABÁ - PA
}

\author{
Kevin Souza da Silva - kevinsouza534@ gmail.com ${ }^{1}$ \\ Ericksson Lucas Silva Roque - erickssonlucas@ hotmail.com ${ }^{1}$ \\ José Carlos da Silva-jose-carlos.silva@unifesspa.edu.br ${ }^{1}$ \\ Elton Rafael Alves-eltonalves@unifesspa.edu.br ${ }^{1}$ \\ João Victor Costa Carmona-jvictor@unifesspa.edu.br ${ }^{I}$ \\ Universidade Federal do Sul e Sudeste do Parál \\ Folha 17, Quadra 4, Lote Especial \\ 68505-080 - Marabá - Pará ${ }^{1}$
}

Resumo: Em busca de um ensino de qualidade nas escolas da rede pública de ensino estadual e municipal do país, deu-se a disseminação do projeto de extensão e visando despertar a vocação de alunos da rede pública de Marabá-PA para as áreas de tecnologias da FACEEL (Faculdade de engenharia da computação e elétrica) da instituição de ensino UNIFESSPA, buscando assim diminuir a lacuna existente entre os alunos da rede públicas de ensino médio profissionalizante e não profissionalizantes da região, através da sinergia proporcionada pelo projeto, onde os alunos se iniciaram e desencadearam na ciência o querer da participação de projetos completos de circuitos eletrônicos em nível de simulação e práticas, além da utilização do próprio aprendizado no cotidiano. Sendo assim, os principais objetivos do mesmo a propagação do ensino e aprendizado dos alunos discentes de graduação da UNIFESSPA em relação a circuitos complexos integrados para com os alunos da rede pública estadual de ensino e que serão base para novos estudos das áreas de tecnologias atuais tais como medição, comunicação e transmissão de dados que são linhas de pesquisas de pesquisadores, professores, e alunos de graduação integrantes do corpo de pesquisa da faculdade (FACEEL).

Palavras-chave: Projetos, Circuitos complexos e Pesquisa.

\section{INTRODUÇÃO}

No âmbito em estudo de projetos de circuitos e dispositivos eletrônicos, discretos ou integrados, o alvo é o desenvolvimento de uma moderna topologia que exponham excelentes desempenhos das quais as existentes, seja na redução de área de circuito, na própria criação das placas e nas elaborações das mesmas a fim de reduzir os custos onerosos propriamente na fabricação de Circuitos Integrados (CI) ou Placas de Circuitos Impressos (PCI), ou na diminuição de consumo de energia, para utilização em materiais ou equipamentos portáteis e entre outros. Neste sentido, o objetivo deste projeto de extensão foi transferir conhecimento de materiais básicos de circuitos integrados e discretos na área de circuitos analógicos e também digitais para novas ferramentas ou equipamentos, ou até mesmo correspondentes, com ênfase no ensino básico sobre os conhecimentos dos materiais eletrônicos de medições de circuitos elétricos (Multímetro, Protoboard, Osciloscópio, Geradores de sinais, etc), (SILVA et al, 2015), (AMARAL et al, 2012).

As instituições de educação de ensino superior, desenvolvem várias atividades de extensão em diversas em áreas, na qual os projetos voltados às áreas tecnológicas têm uma maior qualidade na aplicação (NASCIMENTO, 2017), (PACHECO, 2017). Desse modo, esta proposta de projeto buscou diferenciar-se, oportunizando e proporcionando ao público-alvo a 
discussão desde a aplicação até a disciplina básica (eletrônica) semelhante aos projetos da área de educação (KOCHHANN, 2017).

Os principais propósitos da extensão em relação aos alunos participantes do projeto com os experimentos na prática em laboratório que fazem conjunto com este resumo e as integram aulas experimentais de eletrônica analógica tem por objetivo dar ao estudante alguma familiaridade prática com dispositivos semicondutores de estados sólidos (e.g. diodos e transistores), projeto e prototipação de circuitos analógicos, diodos e transistores, além da utilização de instrumentos elétricos e de procedimentos em laboratórios utilizando-se à prática da eletrônica analógica.

O objetivo é estimular as habilidades práticas do estudante durante o curso e estimulá-lo à pesquisa experimental através de projetos que empreguem a eletrônica de estado sólido incrementando e consolidando o aprendizado adquirido em aulas práticas e teóricas. Ao final do curso, espera-se que o estudante, aluno seja capaz de: projetar, simular e prototipar circuitos simples de eletrônica utilizando analógica de sua própria autoria além de simular utilizando Arduino de qualquer modelo e programando no mesmo. Usar instrumentos de testes e medições elétricas tais como osciloscópios, geradores de sinais, fontes e outros úteis na pesquisa experimental e por fim tenha incrementado sua capacidade de associar o objetivo científico do projeto, obtendo melhores condições de pensar em inovação tecnológica através da eletrônica e suas potenciais aplicações, se sentido estimulado a desenvolvê-la em outras áreas como engenharia da computação, automação e áreas essas afins do cursos de elétrica.

No discorrer do projeto de extensão, exposto neste trabalho, examinou-se conciliar as vertentes da universidade, a pesquisa, o ensino e a extensão, uma vez que, a inserção deste projeto utilizou-se os conhecimentos e colaborações dos projetos de pesquisas que envolve o corpo discente e docente da FACEEL-UNIFESSPA, interdisciplinaridade estimulando-os a desenvolverem trabalhos e pesquisas relevantes para a entidade acadêmica e para a sociedade e comunidade carente que à cerca.

Este trabalho visa apresentar os resultados que são consequências do impacto direto na formação dos discentes da FACEEL, buscando o aprimoramento e aperfeiçoamento técnico, através da disseminação de conhecimentos relacionados a eletrônica aos participantes, especialmente os alunos do ensino médio das escolas públicas municipais de Marabá-PA. Além do mais, os discentes com participação direta no projeto de extensão, participaram da vida de docência, uma vez que desenvolveram projetos e realizarem pesquisas científicas e apresentarem as mesmas e promoverem palestras. Como resultado, o projeto buscou despertar a vocação e atrair os alunos do ensino médio para ingressarem nos cursos de tecnologia da FACEEL-UNIFESSPA.

\section{METODOLOGIA}

Em qualidade de ensino, levantou-se a necessidade de um complemento nas disciplinas de física básica para alunos do ensino médio da rede pública estadual de ensino com o intuito de complementar o aprendizado e conciliar a aula à prática representando o aprendizado em experimentos do que se aprende em sala de aula. Na mesma, o ensino dava-se em princípios básicos de físicas como tensões, correntes, potências, leis de Khirchoff e entre outras.

Na Figura 1 é apresentado um fluxograma demonstrando a maneira como foi conduzida a metodologia de implementação do projeto aplicado nas escolas públicas do município de MARABÁ - PA, onde este tem por título "Inclusão de projetos na área de eletrônica em escolas públicas de Marabá - PA”. 
A metodologia deste projeto de extensão foi dividida em fase (Figura 1):

Figura 1 - Fluxograma de fases de implementação do projeto.

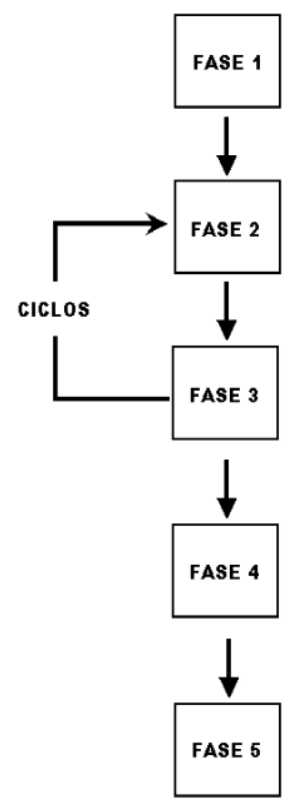

Fonte: Autor.

$\mathrm{Na} 1^{\circ}$ fase, foi escolhida a tecnologia a ser implementada e estudada, através de projetos de circuitos eletrônicos (Discreto ou Integrado) e da disseminação do ensino, para as aplicações no conhecimento dos materiais em energia elétrica (Multímetro, Protoboard, Osciloscópio, Geradores de sinais, etc).

$\mathrm{Na} 2^{\circ}$ fase, deu-se a organização do projeto na FACEEL-UNIFESSPA, que foi dividido em partes técnicas e administrativas: Na parte técnica, executou-se a apresentação do sistema pelo coordenador do projeto (Prof ${ }^{\circ}$ Dr. José Carlos da Silva), durante a qual foram escolhidos temas atuais e desenvolveu-se estudo e projeto de segmentos básicos de circuitos, entre alunos discentes e alunos do ensino médio das escolas públicas de Marabá-PA. Na parte administrativa, o coordenador e os discentes entraram em contato com as diretorias das escolas e entre as visitas a escola "MUNICIPAL DE ENSINO FUNDAMENTAL E MÉDIO ANÍZIO TEIXEIRA" foi firmada uma parceria com a mesma para aplicar o projeto de extensão.

$\mathrm{Na} 3^{\circ}$ fase, foi realizada a disseminação dos projetos de visitas na escola que firmou-se a parceria do projeto e assim deu-se a realização do mesmo. Foram ministradas palestras, aulas práticas e teóricas e oficinas práticas de materiais básicos, assim buscando diferir um pouco da experiência acadêmica que os discentes vivem e assim fazendo com que os participantes 
amadureçam e tenham maturidade perante as suas escolhas nas áreas de tecnologias da FACEEL da UNIFESSPA.

$\mathrm{Na} 4^{\circ}$ fase, foi apreciado o primeiro ciclo do projeto, onde buscou identificar problemas para efetuar melhorias e adequá-las em ciclos futuros.

$\mathrm{Na} 5^{\circ}$ fase, realizou-se a conclusão do projeto referente ao primeiro ciclo, onde foram realizadas as aulas práticas laboratoriais no laboratório da universidade, com o intuito de avaliar os conhecimentos adquiridos no decorrer das aulas práticas e teóricas, e assim posteriormente através desse projeto uma futura entrega de relatório ao fim do curso.

De início, fez-se convite para os alunos em auditório central da escola para posteriormente a apresentação do mesmo e com isso a convocação dos alunos para o projeto.

Figura 2 - Palestra de convite da apresentação do projeto de extensão

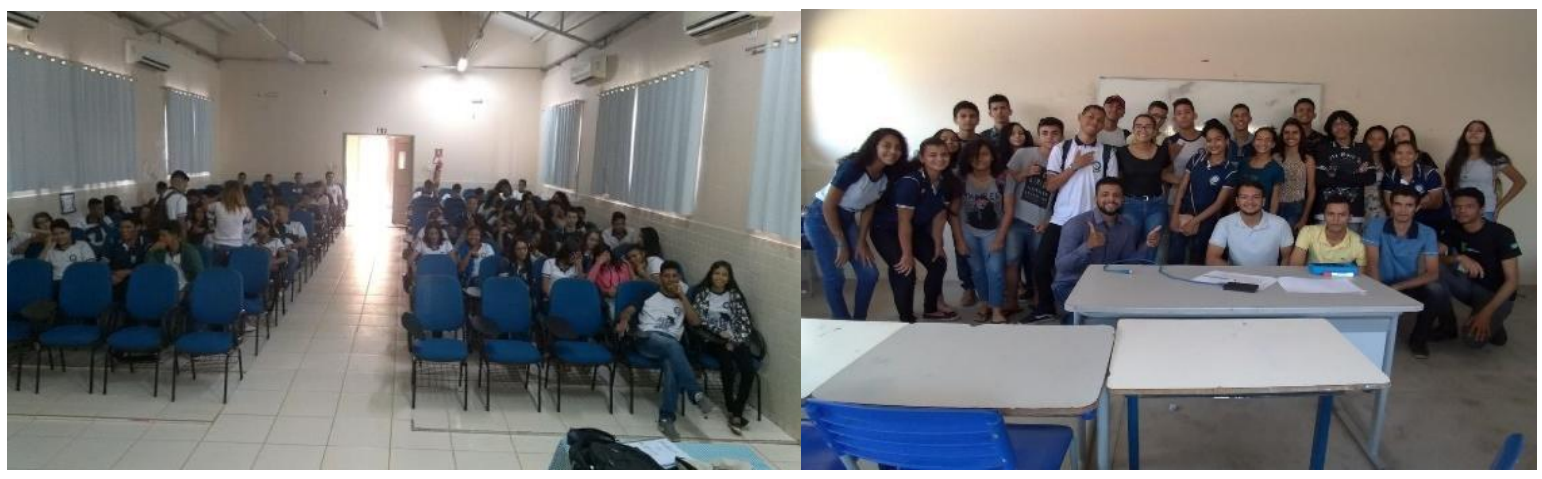

Fonte: Autor.

\subsection{Desenvolvimento do projeto.}

No âmbito de desenvolvimento do projeto houve aulas presenciais ministradas por colaboradores e alunos bolsistas do projeto, para o andamento com êxito. Elaborou-se apostilas e preparou-se kit's Arduino para as aulas de laboratório e práticas, além de projetos feitos pelos próprios discentes do projetos, juntamente com os professores, projetos como: (Ponte H, Sensor de iluminação ou presença, semáforos utilizando Arduino e programação) e etc.

Durante as aulas foi proposto pelos professores do projeto que os alunos deveriam apresentar um trabalho ou proposta de projeto final que seria elaborado com a ajudas dos colaboradores. Desse modo, os mesmos puderam utilizar de suas técnicas e procedimentos típicos de elaboração de projetos e do pensamento científico. Logos, isso seria uma proposta diferente, permitindo que os discentes ampliassem o seu conhecimento e o pensamento científico.

Neste artigo apresenta-se o projeto de extensão em forma de desenvolvimento da perspicácia e de instigar o conhecimento e aguçar a curiosidade dos participantes do projeto como alternativa de sanar a lacuna que os alunos de escolas públicas têm quanto ao ensino e aprendizado, além de os professores do projeto juntamente com os colaboradores passar o conhecimento e vivência do que se aprende dentro da universidade, e da tentativa de otimizar a utilização da ciência compartilhado dentro do ensino público. 
Figura 3 - Ponte H feita pelos alunos do projeto.

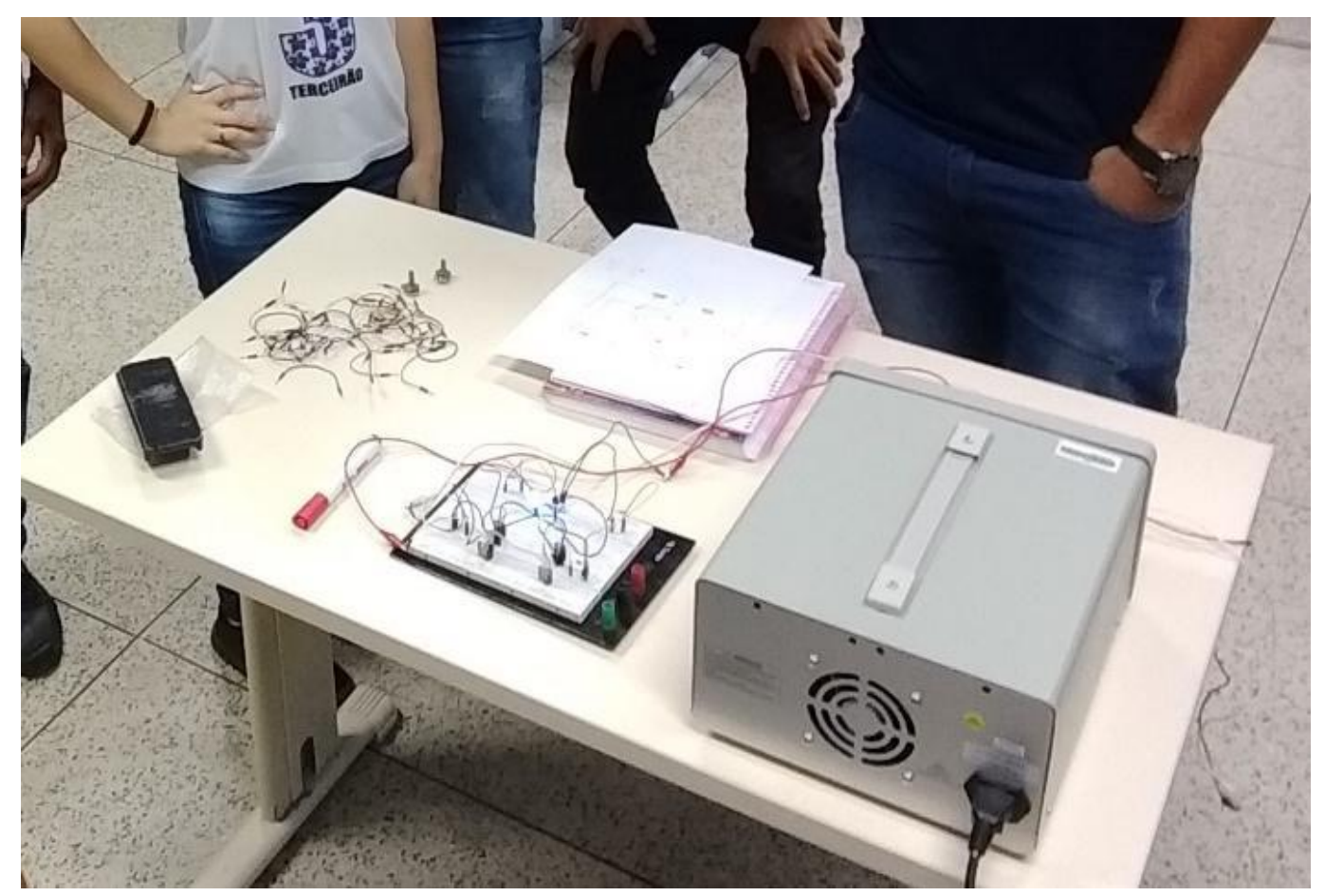

Fonte: Autor.

A Figura 3 apresenta o projeto de uma Ponte H, com o objetivo de demonstrar um motor DC que gira baseado em campos magnéticos gerados pela corrente que passa em suas bobinas. Para variar a velocidade do motor podemos alterar essa corrente que é diretamente proporcional a tensão sobre elas. A figura 4, mostra o movimento giratório que a bobina faz em um campo magnético de um motor DC, movimento esse feito em um motor de ponte $\mathrm{H}$.

Figura 4 - Campo magnético do Motor DC.

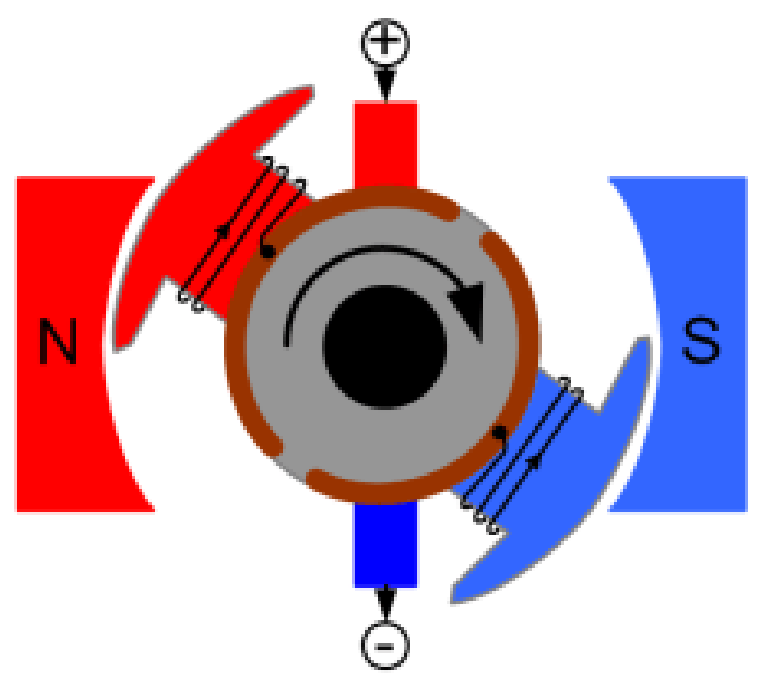

Fonte: UFOP. 
Com a mudança da tensão em um motor DC tipo o modelo acima, teremos uma alteração de velocidade. Para a realização do experimento, deu-se a utilização de Arduino para compor a criação da Ponte $\mathrm{H}$, utilizando de módulos, fios, diodos, resistores, tiristores e outros equipamentos eletro eletrônico para controle de velocidade.

Figura 5 - Esquemático da montagem Ponte H (Controle de Velocidade).

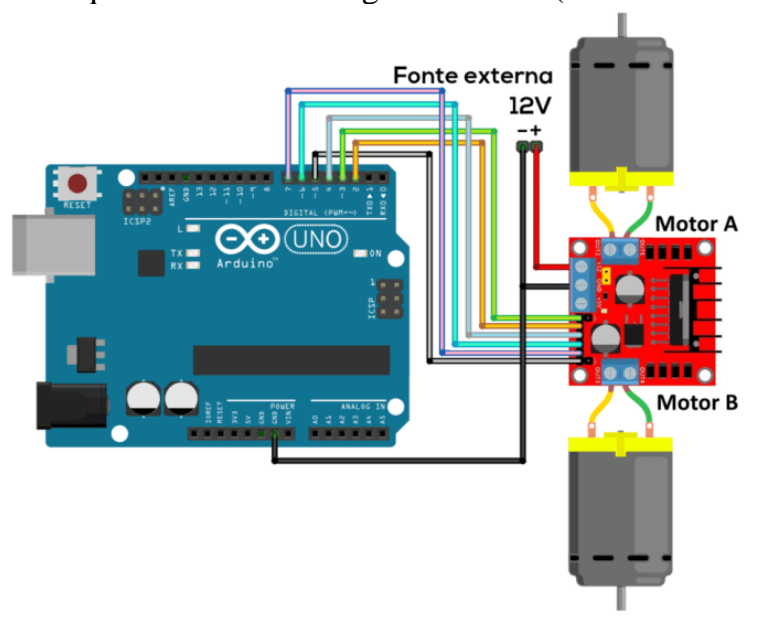

Fonte: Flip-flop.

Com isso, os alunos do projeto montaram o motor de passo em seus módulos Arduino e finalizaram logrando êxito a proposta de montar a Ponte $\mathrm{H}$ e de controlar a velocidade de um motor. Por fim, com o resultado do experimento perfeito, os alunos aprovados ganharam seu certificado final, e habilitados a montagem de circuitos eletrônicos de complexidades relativas. 


\section{RESULTADOS E DISCUSSÕES}

O início dos objetivos alcançados deu-se através da parceria firmada do projeto de extensão pela direção da escola, e o convite dos alunos através de palestras realizadas em auditório, apresentando os projetos na área de eletrônica. Nesta palestra tivemos um total de 58 alunos interessados e motivados no curso oferecido (eletrônica básica - Inclusão de eletrônica nas escolas públicas), Figura 6.

Figura 6 - Palestra de convite da apresentação do projeto de extensão

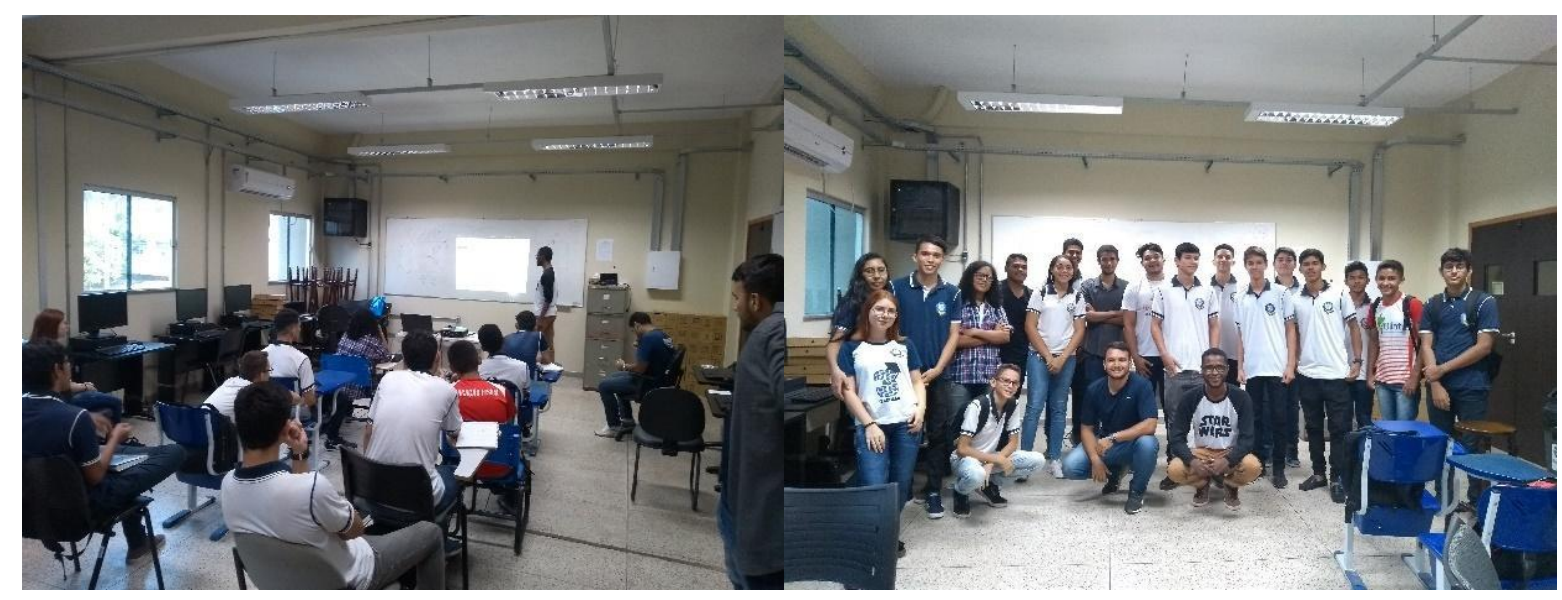

Fonte: Autor.

O desenvolvimento das atividades da extensão desenvolveu-se com cerca dos mesmos 58 alunos entre os turnos da manhã e da tarde, encerrou com 10 ao total final, porém em aula prática de laboratório, compareceram somente 4 alunos. O principal de motivo de evasão dito pelos alunos participantes do projeto deu-se que a escolha para o curso inicialmente centralizouse nos alunos do terceiro ano $\left(3^{\circ}\right)$ que era o público-alvo inicial e a maioria optou, apesar do interesse pelo curso oferecido, a dedicação às suas atividades de cursinho para futuro ENEM. Para minimizar a evasão, foram convidados em um segundo ciclo que irá iniciar, os alunos do primeiro $\left(1^{\circ}\right)$ e segundo $\left(2^{\circ}\right)$ ano da escola que ficaram na lista de espera para futuros ciclos do projeto. E com estes alunos, do primeiro ciclo, o grupo conseguiu, mesmo com todas as dificuldades, finalizar o curso e iniciar a nova turma do segundo semestre, onde foram apresentadas a parte teórica (Figura 7) e práticas através das oficinas, Figura 8.

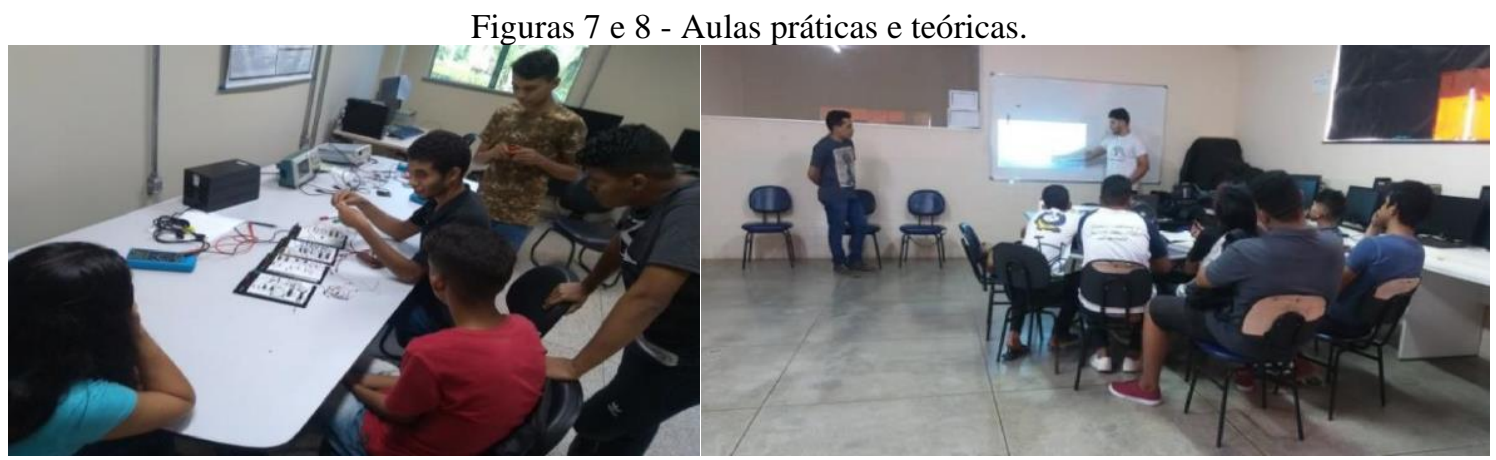

Fonte: Autor. 
Outra conclusão com importante ênfase, deu-se na realização de um questionário para os alunos concederem retorno das atividades de extensão quanto ao curso realizado, e o oferecimento de novos minicursos e questões sobre os cursos da FACEEL e UNIFESSPA, que segue resumidamente na Tabela 1 .

Tabela 1 - Questionário sobre as atividades.

\begin{tabular}{lcc}
\hline Questionamento: & Não & Sim \\
\hline Indicaria os minicursos para outras pessoas? & $0 \%$ & $100 \%$ \\
\hline Você faria um novo minicurso na área de robótica computacional (Arduino)? & $0 \%$ & $100 \%$ \\
\hline Você sabia da existência da UNIFESSPA antes dos minicursos? & $8 \%$ & $92 \%$ \\
\hline $\begin{array}{l}\text { Após conclusão das atividades na área de eletrônica, você teria interesse em ingressar em } \\
\text { algum curso de nível superior da UNIFESSPA? }\end{array}$ & $0 \%$ & $100 \%$ \\
\hline $\begin{array}{l}\text { Após conclusão das atividades na área de eletrônica, você teria interesse em ingressar em } \\
\text { algum curso de nível superior na área de tecnologia (Engenharia Elétrica, Engenharia da } \\
\text { Computação ou Sistema da Informação )? }\end{array}$ & $12 \%$ & $86 \%$ \\
\hline
\end{tabular}

A identificação dos itens a serem avaliados na tabela 1 onde faz uma avaliação a respeito da qualidade do curso apresentado representa um grande desafio aos professores e colaboradores do projeto em relação a qualidade de ensino. Em relação a qualidade do curso ofertado $8 \%$ avaliam como bom, $60 \%$ avaliam o curso como Muito Bom e $32 \%$ como excelente. O trabalho deverá ser feito seguindo as orientações contidas na página do evento. Não serão aceitos trabalhos enviados por correio ou por e-mail. Será acusado, via sistema do evento, o recebimento e a aceitação ou não de cada um dos trabalhos enviados.

Os autores devem combinar com os coautores quem realizará a submissão do trabalho no sistema de submissões.

O trabalho deve ser formatado de acordo com este modelo, pois não haverá revisão após a sua submissão.

\section{CONSIDERAÇÕES FINAIS}

Neste resumo, foram concebidos e apresentados os resultados do desenvolvimento do projeto de extensão da área de eletrônica em temas atuais em áreas de tecnologia. A principal atuação e contribuição do projeto analisando os resultados obtidos (palestras, curso, oficinas) deu-se, que é possível, com melhorias nos futuros ciclos dos projetos de extensão, utilizá-lo como mecanismo de apresentação de projeto nas áreas de tecnologia, bem como, o despertar vocacional dos estudantes das escolas de ensino médio próximo a FACEEL-UNIFESSPA, para um futuro ingresso nos cursos de Engenharia da Computação, Engenharia Elétrica e Sistemas de informações. Levando em consideração o questionário, à uma aceitação em relação a universidade pois $86 \%$ dos alunos do projeto visa pleitear uma vaga na universidade nos cursos de graduação da FACEEL (Engenharia da Computação, Engenharia Elétrica e Sistema de Informação) objetivando-se assim o real sentido do projeto que é despertar a vocação dos alunos para os respectivos cursos de graduação citados. 


\title{
REFERÊNCIAS
}

AMARAL, W A , CASTRO, F , COELHO, S T , GOES, M A , HAMANAKA, C O , I C S , J L E ,, MORAES, W B , PEREIRA, M D, et al A 2.4GHz transceiver for wireless sensor network In: 2012 International Caribbean Conference on Devices, Circuits and Systems (ICCDCS), 2012, Playa del Carmen.

KOCHHANN, M. E. R, “Unifesspa está ai”. Disponível em https://www.unifesspa.edu.br/index.php/noticias/1511-projeto-da-unifesspa-estimulaingresso-de-alunos-da-rede-publica-no-ensino-superior. Acessado em 02 de setembro de 2019.

NASCIMENTO, J. R. Telecomunicações nas escolas - conectando alunos ao mundo tecnológico. Disponível em: http://portal1.iff.edu.br/extensao-e-cultura/projetos-deextensao/projetos-na-area-de-tecnologia-e-producao. Acessado em 02 de setembro de 2019.

SILVA., J. C, SANTOS, C. P., MELO, Wellingotn R. Integração Hardware e Software de uma Plataforma Eletrônica de Comunicação de Dados Via Rede Elétrica. In: Congresso de Inovação Tecnológica em Energia Elétrica - CITENEL - 2015, 2015, Costa do Sauípe - BA.

\section{INCLUSION OF PROJECTS IN THE AREA OF ELETRONICS IN PUBLIC SCHOOLS IN THE MUNICIPALITY OF MARABÁ-PA}

\begin{abstract}
In search of quality education in public schools of states and municipal education in the country, the extension project was disseminated and therefore based on the title of the project and aiming to awaken the vocation of public school students from Marabá-PA to the technology areas of FACEEL (Faculty of Computer and Electrical Engineering) of the UNIFESSPA teaching institution, in order to reduce the existing gap between students from public vocational and non-professional high schools in the region, trough the synergy provided by the project, where students will start and unleash in science the desire to participate in complete electronic circuit projects at the level of simulation and practices, in addition to the use of their own learning on a daily basis spreading the knowledge of the same. The complex and integrated circuits that will be the basis for new for new equipment in the current technology areas of measurement, communication and data transmission that are lines of research by researches, professors, and undergraduate students who are members of the faculty's research body (FACEEL).
\end{abstract}

Keywords: Design, Complex circuits and Research. 